\title{
Erratum
}

\section{Metabolism of Canine Kidneys in Anaerobic Ischemia and in Aerobic Ischemia by Persufflation with Gaseous Oxygen}

\author{
by W. Isselhard, M. Berger, H. Denecke, J. Witte, J. H. Fischer, \\ and H. Molzberger \\ with the cooperation of \\ C. Freiberg, D. Ammermann, and M. Brunke
}

Pflügers Archiv 337, 87-106 (1972)

Page 88, second line from the top. The sentence reads as follow:

It must be attributed to a sufficient aerobiosis in the aerobically ischemic kidney, during which organogenic substrates and substrates brought in by the initial perfusion are utilized.

Prof. Dr. W. Isselhard

Lehrstuhl für Experimentelle Chirurgie der Univ. zu Köln

D-5000 Köln 41

Robert-Koch-Str. 10

Federal Republic of Germany 